\title{
Relationship between Temporal Measurements of Pharyngeal Swallowing and Penetration-Aspiration in Unilateral Stroke Patients
}

\author{
Ikjae Im $^{\mathrm{a}, \mathrm{b}}$, HyangHee Kim ${ }^{\mathrm{c}, \mathrm{d}}$, Hyun-Gi Kim ${ }^{\mathrm{b}}$, Myoung-Hwan Ko ${ }^{\mathrm{b}, \mathrm{e}, \mathrm{f}}$ \\ ${ }^{a}$ Swallowing Research Laboratory, University of Central Florida, FL, USA \\ ${ }^{b}$ Graduate Program in Speech-Language Therapy, Chonbuk National University, Jeonju, Korea \\ ${ }^{c}$ Graduate Program in Speech and Language Pathology, Yonsei University, Seoul, Korea \\ ${ }^{d}$ Department of Physical Medicine and Rehabilitation, Yonsei University College of Medicine, Seoul, Korea \\ 'Department of Physical Medicine and Rehabilitation, Chonbuk National University Medical School, Jeonju, Korea \\ ${ }^{f}$ Research Institute of Clinical Medicine of Chonbuk National University-Biomedical Research Institute of Chonbuk National University Hospital, \\ Jeonju, Korea
}

\begin{abstract}
Correspondence: Myoung-Hwan Ko, MD, PhD Department of Physical Medicine and Rehabilitation, Chonbuk National University Medical School, 20 Geonji-ro, Deokjin-gu, Jeonju 54907 , Korea

Tel: +82-63-250-1795

Fax: +82-63-254-4145

E-mail: mhko@jbnu.ac.kr

Received: May 16, 2017

Revised: August 15, 2017

Accepted: August 21, 2017

-This paper is based on $\mathrm{PhD}$ thesis of first author.

-This research was supported by a grant of the Korea Health Technology R\&D Project through the Korea Health Industry Development Institute (KHIDI), funded by the Ministry of Health \& Welfare, Republic of Korea (Grant No. HI15C1529).
\end{abstract}

Objectives: Although few study have attempted to identify temporal measurements of swallowing in unilateral stroke patients, the relationship between temporal measurements and aspiration-related swallowing dysfunction remain unknown. The aim of this study was to investigate the relationship between temporal measurements of pharyngeal swallowing and aspiration in unilateral stroke patients. Methods: We conducted a prospective study of 60 patients undergoing both videofluoroscopic swallowing examinations and brain magnetic resonance imaging scan studies. Patients were divided into two groups: group 1 included subacute stroke patients with left cerebral hemispheric lesions $(N=27)$ and group 2 included subacute stroke patients with right cerebral hemispheric lesions $(\mathrm{N}=33)$. The results of temporal measurements of swallowing, including pharyngeal transit duration (PTD), initiation laryngeal closure (ILC), and laryngeal closure duration (LCD) and penetration-aspiration, were analyzed during $5-\mathrm{mL}$ thin liquids swallowing task. To determine the optimum cut-off value along with the presence of penetration-aspiration, receiver operating characteristic (ROC) curve analysis was performed. Results: The right cerebral hemispheric lesion group showed significant association with delayed PTD and ILC. The cut-off values for PTD and ILC were 0.71 seconds $(p=.02)$ and 1.25 seconds $(p=.008)$, respectively. Conclusion: ILC is the most valid predictor for penetration-aspiration occurrence in stroke patients with right cerebral hemispheric lesions. Penetration-aspiration events on swallows are affected by delayed laryngeal closure and pharyngeal transit duration.

Keywords: Dysphagia, Deglutition, Stroke, Penetration-aspiration, Pharyngeal transit duration, Initiation of laryngeal closure
대뇌 손상에 의한 뇌졸중은 다양한 기능적 문제를 야기시킨다. 그 중에서도 삼킴 문제는 이들 환자의 $17 \%-50 \%$ 가 경험할 정도로 빈번하게 발생되며(Langdon \& Blacker, 2010; Mann, Hankey, \& Cameron, 2000; Martino et al., 2005), 80\%-90\%는 편측 손상에서 기인한다(Daniels, Foundas, Iglesia, \& Sullivan, 1996; Gordon,
Hewer, \& Wade, 1987; Suntrup-Krueger et al., 2017). 선행연구에 따르면, 이들의 삼킴 문제는 손상된 반구의 위치에 따라 다르게 나 타나는데 좌반구 손상 환자는 구강 단계의 삼킴 문제가 두드러진 데 반면 우반구 손상 환자는 인두 단계의 삼킴 문제가 두드러졌다 (Daniels et al., 1996; Robbins \& Levine, 1988; Robbins, Levine, Ma- 
ser, Rosenbek \& Kempster, 1993; Smithard, O’Neill, Martin, \& England, 1997). Martin과 Sessle (1993)의 연구에서는 이러한 차이 가 좌반구는 구강 삼킴 우세 반구이고 우반구는 인두 삼킴의 우세 반구이기 때문이라고 설명하고 있다. 또한 말 산출 시에 뇌 활성화 를 보인 영역과 삼킴 시에 활성화를 보인 영역이 대부분 일치하였다 고 보고하였는데, 이는 언어와 삼킴은 대뇌에 의해 유사한 방식으 로 통제되기 때문이라고 제안하였다(Mosier, Liu, Maldjian, Shah, \& Modi, 1999).

한편, 뇌졸중 환자의 삼킴 문제는 저하된 삼킴 효율성(swallowing efficient)과 침습 및 흡인 현상으로 특징지어진다(Im, 2017). 선 행연구에 따르면 뇌졸중 환자의 인두통과시간과 후두폐쇄지속시 간은 정상인 보다 길었는데(Logemann et al., 1993; Power et al., 2009), 이는 동일한 운동을 뇌졸중 환자가 더 오랜 시간 동안 수행 했다는 것을 의미하므로 이들의 삼킴 효율성은 상대적으로 낮다고 할 수 있다. 뇌졸중 환자들의 저하된 삼킴 효율성은 감각 기능의 저 하, 예비력 감소, 근육의 불협응 등에서 그 원인을 찾을 수 있으며 삼킴 시간을 측정함으로써 평가할 수 있다. 삼킴 시간의 측정 방법 은 비디오투시조영삼킴 검사의 자료(videofluoroscopic swallowing examination, VFSE)상에 두 구간(시작점과 끝점)을 지정한 뒤 이 곳을 (1) 음식물이 이동하는 데 소요한 시간을 분석하거나, (2) 특 정한 삼킴 운동(specific event)이 행해진 시간을 분석하여 초 단위 로 나타낸다(Logemann, Pauloski, Rademaker, \& Kahrilas, 2002). 삼킴 시간의 하위 변수로는 구강통과시간, 인두통과시간, 후두폐 쇄유발시간, 후두폐쇄지속시간 등이 있으며 대체로 정상인은 모든 시간에서 1 초 미만의 시간을 보인다. 삼킴 시간 측정 연구는 연구자 의 의도 및 목적에 따라 측정하는 하위 변수를 달리하기도 하는데, 최근에는 인두 단계의 삼킴 시간에 집중하여 분석하는 경향이 관 찰된다(Im, Kim, Oommen, Kim, \& Ko, 2012; Kim, 2009; Lee, 2012). 상대적으로 인두 단계의 삼킴 시간이 침습 및 흡인의 원인을 잘 설명하기 때문인데(Perlman, Booth, \& Grayhack, 1994; Power et al., 2009), 이는 구강 단계의 삼킴 효율이 저하되었을지라도 침습 및 흡인이 발생되지는 않는 것과도 연관이 있다. 이외에 삼킴 시간 은 음식물의 점도 및 양, 연령 등에 의해 영향을 받는다고 하며 침습 및 흡인 위험도를 감소시키는 변인들에 대한 논의도 이루어지고 있 다(Bisch, Logemann, Rademaker, Kahrilas, \& Lazarus, 1994; Logemann et al., 2000). 다음으로 침습 및 흡인에 대해 살펴보면, 흡인 은 음식물이 기도로 잘못 들어간 것으로, 침습은 종종 흡인의 원인 이 되며, 흡인의 원인으로는 상부호흡계에 위치한 근육및 구조물들 의 부적절한 삼킴 운동 등이 있다. 침습 및 흡인의 원인으로는 상부 호흡계에 위치한 근육 및 구조물들의 부적절한 삼킴 운동 등이 있
다(Rosenbek, Robbins, Roecker, Coyle, \& Wood, 1996). 침습 및 흡 인은 폐렴에도 심각한 영향을 끼치는 것으로 알려져 있고(Loeb, Becker, Eady \& Walker-Dilks, 2003; Marik, 2001), 폐렴은 뇌졸중 환자의 사망 위험도를 2 배 이상 가중시키기 때문에(Finlayson et al., 2011; Martino et al., 2005) 침습 및 흡인의 위험 요소를 제거하 거나 예측하려는 노력이 시급하다. 그러나 아직까지 침습 및 흡인 의 원인을 규명하는 방법은 VFSE를 비롯한 이미지 연구에 국한되 어있고 식이를 조절하거나 비위관 식이를 권고하는 등의 침습 및 흡 인 위험도를 제거하는 방법이 유일하다. 따라서 침습 및 흡인을 예 측하려는 시도가 필요한데 정확한 침습 및 흡인 발생 시각을 규명 해야 한다는 점에서 삼킴 시간 측정 연구는 매우 적합한 방법론이 라고 할 수 있다. 하지만 지금까지의 삼킴 시간 연구는 뇌졸중 환자 와 정상인의 삼킴 시간 측정하여 그들의 삼킴 효율성을 비교하거 나 뇌졸중 환자라 하더라도 비흡인자와 흡인자 간의 삼킴 시간을 비교하는 등의 대조 연구에 치우쳐 있다(Choi, Ryu, Kim, Kang, \& Yoo, 2011; Logemann et al., 1993; Park, Kim, \& McCullough, 2013). 이러한 대조 연구는 뇌졸중 환자의 삼킴 효율성이 정상인보 다 얼마나 낮은지를 조사하는 것에는 효과적이지만 침습 및 흡인 의 원인을 조사하고 예측하기엔 한계가 있다.

이에 따라 본 연구는 뇌졸중 환자의 침습 및 흡인 현상에 주목하 고 이것을 예측하기 위해 삼킴 시간을 측정하고자 한다. 그런데 대 뇌의 편측성에 따라 삼킴 우세 반구 또한 존재할 가능성이 있으므 로, 손상 반구 위치에 따른 삼킴 시간과 흡인 및 침습 여부를 조사 하고자한다. 더불어 뇌졸중은 특성상 발병 후 경과시간은 삼킴 문 제에도 영향을 줄 수 있기 때문에, 발병 후 경과시간이 90일 미만의 아급성 환자로 대상자를 한정하고자 한다.

정리하면, 본 연구의 구체적인 연구 질문은 다음과 같다.

첫째, 인두통과시간, 후두폐쇄유발시간과 후두폐쇄지속시간에 서 좌반구 손상 집단과 우반구 손상 집단 간 차이가 유의한가?

둘째, 3 가지의 삼킴 시간 중 좌반구 손상 집단과 우반구 손상 집 단에서 유의하게 침습 및 흡인을 예측한 삼킴 시간은 무엇인가?

\section{연구방법}

\section{연구대상자}

본 연구는 2011년 3월 1일부터 2013년 3월 29일까지 전북대학교 병원에 내원한 환자 중 대뇌의 한쪽 반구만 손상된 뇌졸중 환자 총 60 명을 대상으로 하였다. 연구 대상자의 선정 기준은 (1) 편측 반구 손상으로 인한 뇌졸중 환자, (2) 뇌졸중 진단 후 VFSE검사일까지 의 기간이 8 일에서 90 일 미만의 아급성기 환자, (3) Glasgow Coma 
Ikjae Im, et al. • Relationship between Temporal Measurements and Penetration-aspiration

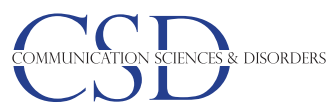

Scale이 10 이상인 환자이다. 이들 대상자는 좌반구 손상 집단(27 명; 평균 연령 62.59세)과 우반구 손상 환자 집단(33명; 평균 연령 66.30세)으로 분류하였으며 대상자 정보는 Table 1에 제시하였다. 본 연구는 전북대학교병원 생명의학연구윤리심의위원회의 심의 를 받았다(CBIRB No. 910-116).

\section{VFSE}

모든 대상자들의 삼킴 기능 평가를 위하여 VFSE를 수행하였다. 환자들은 검사실에 입실하여 준비된 의자에 착석하였고 재활의학 과 전공의 지시에 따라 준비된 음식물을 삼켰다. 검사에 사용된 기 기는 Sonial Vision Versa 100I/DAR-8000i (Shimadzu Medical Systems, Kyoto, Japan)이며 촬영으로 얻어진 X-ray 자료는 외부 입 력 장치에 저장되었다. 삼킴 검사에는 물과 조영제(barium sulfate 96 g/100 g; Solotop HD, Taejoon Pharm, Seoul, Korea)가 섞인 혼 합물 $5 \mathrm{~mL}$ 가 사용되었으며, 이때 바륨의 최대 농도는 $150 \% \mathrm{w} / \mathrm{v}$ 이 하로 조절하였다. 혼합물의 점도는 $3 \mathrm{cP}$ 이었으며(Brookfield viscometer, Middleboro, MA, USA), 이는 물(o cP)과 비슷한 수준의 점도 이다. 점도는 한국화학융합시험연구원에 의뢰하여 측정하였다.

\section{삼킴 시간 및 침습 및 흡인 유무 분석}

삼킴 변수는 총 3 가지로 (1) 인두통과시간, (2) 후두폐쇄유발시간,

Table 1. Participants' demographics

\begin{tabular}{|c|c|c|}
\hline & $\begin{array}{l}\text { Left cerebral } \\
\text { hemispheric lesion group } \\
(\mathrm{N}=27)\end{array}$ & $\begin{array}{l}\text { Right cerebral hemi- } \\
\text { spheric lesion group } \\
\qquad(\mathrm{N}=33)\end{array}$ \\
\hline Age (yr) & $62.59 \pm 12.53$ & $66.30 \pm 13.40$ \\
\hline \multicolumn{3}{|l|}{ Sex } \\
\hline Female & $13(48)$ & $20(61)$ \\
\hline Male & 14 (52) & $13(39)$ \\
\hline \multicolumn{3}{|l|}{ Stroke type } \\
\hline Ischemic & $17(48)$ & $22(67)$ \\
\hline Hemorrhagic & $10(52)$ & $10(30)$ \\
\hline Mixed & $0(0)$ & $1(3)$ \\
\hline Admission day & $31.63 \pm 23.74$ & $33.94 \pm 24.64$ \\
\hline
\end{tabular}

Values are presented as mean \pm SD or number (\%).
(3) 후두폐쇄지속시간이다. 각 삼킴 시간은 VFSE검사의 동영상 자 료를 1 초 당 30 장의 프레임으로 분할하여 측정하였으며 이때 사용 한 프로그램은 Final Cut Pro X (Apple Inc., Cupertino, CA, USA) 이다. 인두통과시간은 음식물이 인두 단계의 해부학적 시작점(아 래턱 뼈)에서 끝점(상부식도괄약근)까지 이동하는데 소요한 시간 을 측정한 것이다. 이를 측정하기 위해 음식물이 아래턱 뼈를 지나 는 화면이 촬영된 프레임과 음식물이 상부식도괄약근을 지나는 현상이 촬영된 2장의 프레임을 선별하였고, 이 두 프레임 간 시간적 차이를 분석하였다. 후두폐쇄유발시간은 음식물이 아래턱 뼈를 지 난 시각에서부터 후두개와 피열 연골이 서로 만나는 시각까지의 시간(time duration)을 측정하였고, 후두폐쇄지속시간은 후두개와 피열 연골이 서로 만나는 시각에서부터 서로 떨어지는 시각까지의 시간을 측정하였다(Figure 1). 삼킴 시간 측정의 구체적인 기준은 Table 2에 기술하였다(Logemann et al., 2000; Power et al., 2009; Robbins, Hamilton, Lof, \& Kempster, 1992).

침습 및 흡인 유무를 분석하기 위해 모든 피검자들의 VFSE 동영 상 자료를 조사하여 침습-흡인 척도(Penetration-Aspiration Scale,

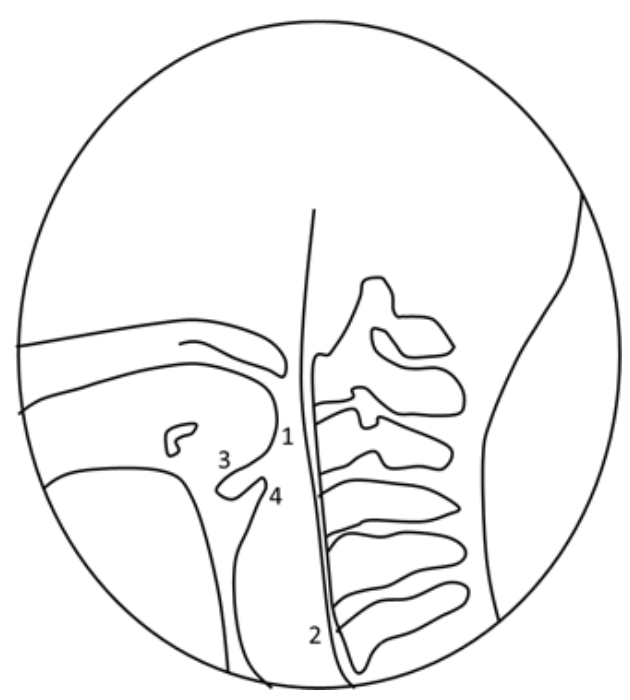

Figure 1. Lateral fluoroscopic view ( $1=$ ramus of mandible; $2=$ upper esophageal sphincter; 3 =arytenoids; 4 = epiglottis).

Table 2. Criteria for VFSE and penetration-aspiration

\begin{tabular}{lll}
\hline Definition & \multicolumn{2}{c}{ Criteria for time duration } \\
\cline { 2 - 3 } & \multicolumn{1}{c}{ Onset point } & Offset point \\
\hline Pharyngeal transit duration & Bolus passing ramus of mandible & Bolus passing upper esophageal sphincter \\
Initiation of laryngeal closure & Bolus passing ramus of mandible & First contact of arytenoids and epiglottis \\
Laryngeal closure duration & First contact of arytenoids and epiglottis & Final contact of arytenoids and epiglottis \\
\hline
\end{tabular}

VFSE= videofluoroscopic swallowing examination 
$\mathrm{PAS}$ )에 따라 침습 및 흡인의 양상을 1-8점으로 기록하였다. 이 척 도는 침습 및 흡인 문제를 정량화하여 나타내는 데 효과적인 척도 로써 평가의 타당도가 높고 검사자 간 신뢰도 또한 높은 것으로 알 려져 있다(Robbins, Coyle, Rosenbek, Roecker, \& Wood, 1999).

\section{신뢰도}

전체 자료의 $50 \%$ 에 해당되는 30 명의 인두통과시간, 후두폐쇄유 발시간, 후두폐쇄지속시간과 침습 및 흡인 평가는 동일한 주 검사자 에 의해 재분석되었고 이때의 신뢰도는 $94 \%$ 이었다 $(r=.94, p<.01)$. 평가자 간 신뢰도 분석을 위해 훈련된 보조 검사자가 전체 자료의 $15 \%$ 에 해당되는 9 명의 자료를 무작위로 선정하여 분석하였고, 주 검사자와 보조 검사자 간 신뢰도는 $94 \%$ 이었다 $(r=.94, p<.01)$.

\section{통계분석}

손상 반구에 따라 삼킴 시간에서 차이가 있는지 알아보기 위하 여 Mann-Whitney 분석을 실시하였고, 3가지의 삼킴 시간이 침습 및 흡인에 미치는 영향을 조사하기 위하여 receiver operating characteristic curve (ROC) 분석도 함께 실시하였다. ROC 분석의 경우, 집단에 따라 ROC 곡선 아래의 면적 값(area under curve, AUC)이 0.7 이상으로 나온 삼킴 시간이 있는지를 살펴보았다. 이러한 조사 는 삼킴 시간과 침습 및 흡인 간 상관성을 조사하기 위함으로 AUC 값이 0.7 이상으로 나온 경우 두 변수 간 상관 관계가 있는 것으로 가정하였다. 또한 통계적으로 유의한 상관 관계를 보인 시간에 한

Table 3. Comparison of temporal measurements between lesion side groups

\begin{tabular}{lcc}
\hline Variables & $\begin{array}{c}\text { Left cerebral hemi- } \\
\text { spheric lesion group }\end{array}$ & $\begin{array}{c}\text { Right cerebral hemi- } \\
\text { spheric lesion group }\end{array}$ \\
\hline Pharyngeal transit duration (s) & $.79 \pm .40$ & $.77 \pm .35$ \\
Initiation of laryngeal closure & $.79 \pm .72$ & $1.15 \pm .98$ \\
Laryngeal closure duration & $.62 \pm .26$ & $.53 \pm .17$ \\
\hline
\end{tabular}

Values are presented as mean $\pm S D$.
해 어떤 시점에서 침습 및 흡인이 발생(cut-off time)되는지를 추정 하였다. 침습 및 흡인 유무는 PAS에 따라 3 이상의 값을 나타낸 경 우로 지정하였다. 모든 자료는 SPSS version 23.0 (SPSS Inc., Chicago, IL, USA)을 사용하여 분석하였다.

\section{연구결과}

좌반구 손상 집단의 인두통과시간은 평균 $0.79 \pm 0.40$ 초, 우반구 손상 집단은 평균 $0.77 \pm 0.35$ 초로 관찰되었다. 후두폐쇄유발시간 의 경우 좌반구 손상 집단이 평균 $0.79 \pm 0.72$ 초, 우반구 손상 집단 은 평균 $1.15 \pm 0.9$ 초로 관찰되었다. 후두폐쇄지속시간의 경우 좌반 구 손상 집단의 평균 $0.62 \pm 0.2$ 초, 우반구 손상 환자 집단은 평균 $0.53 \pm 0.1$ 초로 관찰되었다. 각 집단 간 삼킴 시간은 통계적으로 유 의한 차이가 없었다. 각 집단 간 삼킴 시간은 Table 3에 기술하였다.

두 집단에 따라 3 가지의 삼킴 시간 중 어떠한 삼킴 시간이 침습 및 흡인과 상관 관계가 있는지를 살펴보기 위하여 ROC 분석을 실 시하였다. 그 결과, 좌반구 손상 집단의 모든 삼킴 시간의 $\mathrm{AUC}$ 값 이 0.7 미만인 것으로 나타나 삼킴 시간과 침습 및 흡인 간 유의한 상관 관계를 찾을 수 없었다.

우반구 손상 집단의 경우, 인두통과시간(AUC $=0.78$; 95\% confidence interval, 0.58-0.96; $p=.02$ )과 후두폐쇄유발시간(AUC= $0.83 ; 95 \%$ confidence interval, $0.64-1 ; p=.008)$ 은 침습 및 흡인과 통계적으로 유의한 상관 관계가 있는 것으로 나타났다(Table 4). 이 에 따라 인두통과시간과 후두폐쇄유발시간이 어느 정도의 지연을 보이면 침습 및 흡인이 발생 되는지를 조사하기 위해 침습 및 흡인

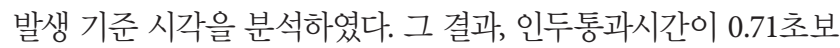
다 지연되면 침습 및 흡인이 발생되며(sensitivity $=0.71$, specificity $=0.65)$, 후두폐쇄유발시간은 1.25 초보다 지연되면 침습 및 흡인 발생이 되었다(sensitivity $=0.86$, specificity $=0.85)$ (Figure $2 \mathrm{~A}$, 2B).

Table 4. Sensitivity and specificity for penetration-aspiration across groups

\begin{tabular}{|c|c|c|c|c|c|c|}
\hline Groups & Variables & AUC & Sensitivity & Specificity & $p$-value & Cut-off time (s) \\
\hline \multirow[t]{3}{*}{ Left cerebral hemispheric lesion group } & PTD & .31 & - & - & .17 & - \\
\hline & ILC & .25 & - & - & .07 & - \\
\hline & LCD & .45 & - & - & .72 & - \\
\hline \multirow[t]{3}{*}{ Right cerebral hemispheric lesion group } & PTD & .77 & .71 & .65 & $.02^{*}$ & .71 \\
\hline & ILC & .83 & .85 & .86 & $.008^{* *}$ & 1.25 \\
\hline & LCD & .48 & - & - & .87 & - \\
\hline
\end{tabular}

$\mathrm{AUC}=$ area under curve; $\mathrm{PTD}=$ pharyngeal transit duration; $\mathrm{ILC}=$ initiation of laryngeal closure; $\mathrm{LCD}=$ laryngeal closure duration . ${ }^{*} p<.05,{ }^{* *} p<.01$. 

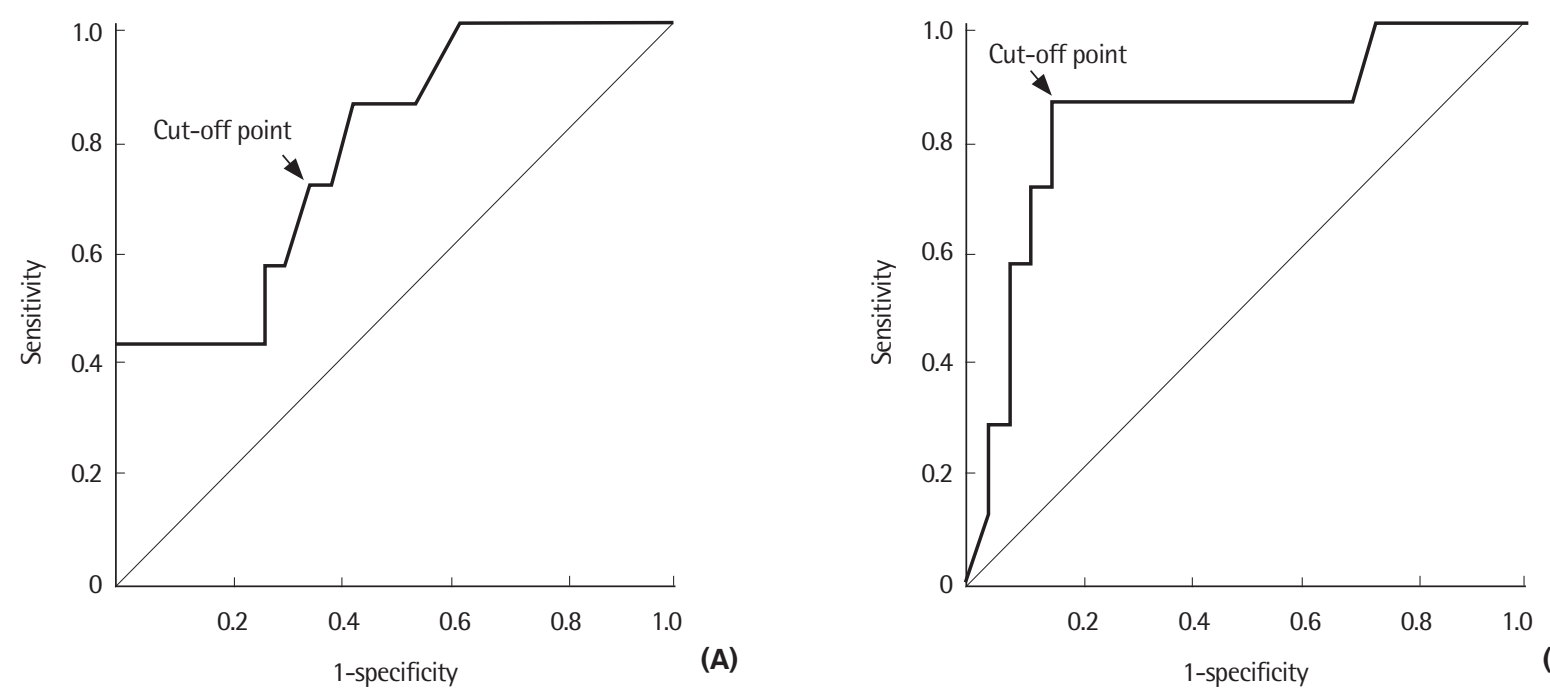

(B)

Figure 2. Receiver operating characteristic (ROC) curve of cut-off time for (A) pharyngeal transit duration ( $\mathrm{AUC}=0.78 ; 95 \% \mathrm{Cl}, 0.58-0.96 ; p=.02)$ and $(\mathrm{B})$ initiation of laryngeal closure (AUC=0.83; 95\% Cl, 0.64-1; $p=.008$ ) with right cerebral hemispheric group.

\section{논의 및 결론}

본 연구는 편측 반구 손상 뇌졸중 환자를 대상으로 손상 반구 위치에 따라 3 가지의 삼킴 시간에서 차이가 있는지를 살펴보고, 이 시간 중 어떠한 삼킴 시간이 침습 및 흡인에 영향을 주는지 알아보 고자 하였다. 그 결과 첫째, 뇌졸중 환자들의 삼킴 시간은 집단 간 통계적으로 유의한 차이를 보이지 않았다. 이러한 이유는 적은 양 의 액체 $(5 \mathrm{~mL})$ 를 삼킬 때의 삼킴 효율성은 두 집단 간 유사하였기 때문으로 추측된다. Robbins 등(1993)의 연구에서는 높은 점도의 음식물을 삼키는 과제에서 우반구 및 좌반구 손상 집단 간 삼킴 시 간에서 차이가 있었지만, 낮은 점도의 액체 삼킴 과제에서는 본 연 구의 결과와 마찬가지로 차이가 없었다. 또한 뇌졸중 환자라 할지 라도 적은 양을 삼키는 과제에서의 삼킴 시간은 정상 대조 집단과 뇌졸중 집단 간 차이가 없었다는 Logemann 등(1993)의 연구결과 를 종합해 볼 때, 본 연구에서 사용한 적은 양과 낮은 점도의 액체 는 집단 간 삼킴 시간의 차이를 비교하는데 제한적이었던 것으로 생각된다.

둘째, 우반구 손상 집단의 인두통과시간과 후두폐쇄유발시간은 침습 및 흡인과 상관 관계가 있었다. 흥미롭게도 이러한 결과는 우 반구 손상 집단에서만 발견할 수 있었다는 것인데, 이에 따른 해석 은 인두통과시간과 후두폐쇄유발시간이 모두 인두 단계의 삼킴 시 간이라는 점에 주목해서 살펴보고자 한다. 삼킴 운동과 관련하여 대뇌 편향성을 조사한 연구에 따르면, 좌반구는 구강 단계의 삼킴 운동과 같이 수의적인 운동에 편향되어 있는 반면 우반구는 인두
단계의 삼킴 운동과 같은 불수의적인 운동에 편향되어 있다고 한 다(Mosier et al., 1999; Daniels, Corey, Fray, DePolo \& Foundas, 2006). 이외에도 우반구 손상 환자는 후두개의 불완전한 움직임 또 는 빈번한 침습 및 흡인 현상을 나타낼 수 있는데(Perlman et al., 1994; Power et al., 2009; Robbins et al., 1993), 이것은 이 운동에 편향 되어 있는 대뇌의 기능이 소실되었기 때문이라고 보고된 바 있다 (Robbins \& Revin, 1988). 이러한 영향에 따라 우반구 손상 환자는 인두 단계의 음식물을 식도로 이동시키는 기능, 후두를 폐쇄 시키는 기능 등의 효율이 저하되었고 이는 침습 및 흡인에도 영향을 주었다 고 생각된다. 더불어 이 결과는 우반구가 인두 단계의 삼킴 우세 반 구임을 확인하는 근거를 마련했다는 점에서 그 의의를 갖는다.

마지막으로, 우반구 손상 집단이 액체 $5 \mathrm{~mL}$ 를 삼킬 때 각각 후두 폐쇄유발시간은 1.25 초, 인두통과시간은 0.71 초보다 길면 침습 및 흡인이 발생되었다. 후두폐쇄유발시간은 음식물의 인두 단계 진입 에 따른 후두 폐쇄 운동이 얼마나 빠르게 일어나는지를 조사하기 위한 변수이다. 이 시간은 음식물이 아래턱 뼈를 지난 순간에서부 터 후두개와 피열 연골이 서로 만나는 데까지 소요한 시간을 측정 하였는데, 이 측정값이 작을수록 후두 폐쇄 운동이 빠르게 일어났 다는 것을 의미한다. 선행연구에서 후두폐쇄유발시간은 뇌졸중 환 자가 정상인보다 길고 흡인자는 비흡인자보다 더 길었다(Inamoto et al., 2013; Park, Kim, Ko, \& McCullough, 2010; Power et al., 2009). 또한 후두폐쇄유발시간과 침습 및 흡인과의 상관 관계를 조 사한 선행 연구에서는 우반구 손상 환자와 유사하게 음식물이 인 두 단계로 진입 후 1.5-2초 이내에 후두 폐쇄가 일어나야 한다고 제 
안하였다(Kim, \& McCullough, 2007; Park et al., 2010). 이러한 결 과들을 종합해보았을 때, 후두폐쇄유발시간은 침습 및 흡인을 예 측하는 가장 타당하고 효과적인 변수라고 제안한다. 한편, 인두통 과시간은 음식물이 아래턱 뼈의 가장자리에서부터 상부식도괄약 근까지 이동하는데 소요한 시간을 측정한 것으로, 이 시간은 인두 단계의 전반적인 삼킴 효율성을 살펴보는데 이용된다. 정상인의 인 두통과시간은 1초 이내이며(Bisch et al., 1994; Logemann et al., 2002; Robbins et al., 1992), 청년층은 노년층의 인두통과시간인 0.80 초보다 짧고, 남성이 여성의 0.80 초보다 짧다고 보고된 바 있다 (Im et al., 2012). 또한 뇌졸중 환자의 인두통과시간은 정상인보다 길었고, 흡인자가 비흡인자보다 길었다고 보고되었다(Choi et al., 2011; Logemann et al., 1993). 그러나 아직까지 인두통과시간과 침 습 및 흡인 간 상관 관계에 대해 구체적으로 보고된 바가 없어 본 연 구의 결과를 해석하는 것에는 데에는 한계가 있다. 하지만 대체로 0.80 초의 인두통과시간을 보고한 선행연구의 결과와 비교하였을 때, 우반구 손상 환자의 침습 및 흡인 발생 시각으로 제안한 0.71 초 는 상당히 설득력이 있어 보인다. 그러나 추후 연구를 통해 명확한 근거를 마련하는 것이 요구된다.

본 연구는 편측 손상 뇌졸중 환자를 대상으로 손상 위치에 따라 삼킴 문제가 다른지를 살펴보았고, 우반구 손상 환자의 인두 단계 삼킴 문제를 확인하였다는 데에 임상적 의의가 있다. 특히, 인두통 과시간과 후두폐쇄유발시간은 각각 0.71 초와 1.25 초보다 지연되면 침습 및 흡인이 발생된다고 예측한 결과는 우반구 손상 환자의 삼킴 문제를 예측하고 중재 방안을 마련하는 과정에서 언어재활사는 어 떠한 삼킴 시간을 우선적으로 살펴보아야 하는지에 관한 정보를 제 공하였다. 언어재활사에 의한 삼킴 연구는 뇌졸중 환자의 말.언어 장애 연구에 비해 매우 저조한 현 실정에서 본 연구의 이러한 시도 로부터 삼킴 연구에 관한 지속적인 논의가 이루어지기를 기대한다.

연구의 제한점으로는 삼킴 우세 반구를 조사하기 위한 사전조 사로써, 피검자들의 손잡이 및 언어 우세 반구등에 대한 사전 검증 이 이루어지지 않았다는 점이다. 또한 두 집단 간 뇌졸중 중증도가 동질하였는지에 관한 검증이 이루어지지 않았다. 뇌졸중은 분류 및 경중에 따라 문제의 양상이 다를 수 있기 때문에 후행연구에서 는 피검자들의 손잡이 정보, 말.언어장애 및 뇌졸중 중증도에 대한 광범위한 조사가 이루어져야 할 것으로 생각된다. 마지막으로 두 집단 삼킴 문제를 평가함에 있어 삼킴 효율성과 침습 및 흡인 측면 만을 조사하였다는 점이다. 뇌졸중 환자의 삼킴 양상은 개인차가 크고 그 양상이 다양하기 때문에 두 측면만 다룬 정보는 삼킴 장애 를 판별하거나 삼킴 문제의 중증도를 파악하지 못하는 한계가 있 다. 이를 바탕으로 후행연구에서는 뇌졸중 환자의 삼킴 문제에 대
한 심층적인 접근이 필요할 것으로 사료된다.

\section{REFERENCES}

Bisch, E. M., Logemann, J. A., Rademaker, A. W., Kahrilas, P. J., \& Lazarus, C. L. (1994). Pharyngeal effects of bolus volume, viscosity, and temperature in patients with dysphagia resulting from neurologic impairment and in normal subjects. Journal of Speech, Language, and Hearing Research, 37, 1041-1059.

Choi, K. H., Ryu, J. S., Kim, M. Y., Kang, J. Y., \& Yoo, S. D. (2011). Kinematic analysis of dysphagia: significant parameters of aspiration related to bolus viscosity. Dysphagia, 26, 392-398.

Daniels, S. K., Corey, D. M., Fraychinaud, A., DePolo, A., \& Foundas, A. L. (2006). Swallowing lateralization: the effects of modified dual-task interference. Dysphagia, 21, 21-27.

Daniels, S. K., Foundas, A. L., Iglesia, G. C., \& Sullivan, M. A. (1996). Lesion site in unilateral stroke patients with dysphagia. Journal of Stroke and Cerebrovascular Diseases, 6, 30-34.

Finlayson, O., Kapral, M., Hall, R., Asllani, E., Selchen, D., \& Saposnik, G. (2011). Risk factors, inpatient care, and outcomes of pneumonia after ischemic stroke. Neurology, 77, 1338-1345.

Gordon, C., Hewer, R. L., \& Wade, D. T. (1987). Dysphagia in acute stroke. British Medical Journal (Clinical Research Ed), 295, 411-414.

Im, I. (2017). The effects of bolus viscosity and volume on temporal measurements and aspiration of oropharyngeal swallowing in supratentorial stroke patients. Journal of Speech-Language \& Hearing Disorders, 26, 133-141.

Im, I., Kim, Y., Oommen, E., Kim, H., \& Ko, M. H. (2012). The effects of bolus consistency in pharyngeal transit duration during normal swallowing. Annals of Rehabilitation Medicine, 36, 220-225.

Inamoto, Y., Saitoh, E., Okada, S., Kagaya, H., Shibata, S., Ota, K., Palmer, J. B. (2013). The effect of bolus viscosity on laryngeal closure in swallowing: kinematic analysis using 320-row area detector CT. Dysphagia, 28, 33-42.

Kim, H., Chung, C. S., Lee, K. H., \& Robbins, J. (2000). Aspiration subsequent to a pure medullary infarction: lesion sites, clinical variables, and outcome. Archives of Neurology, 57, 478-483.

Kim, Y. (2009). Temporal and biomechanical measurements of upper esophageal sphincter (UES) opening in normal swallowing. Korean Journal of Communication Disorders, 14, 109-116.

Kim, Y., \& McCullough, G. H. (2007). Stage transition duration in patients poststroke. Dysphagia, 22, 299-305. 
Ikjae Im, et al. • Relationship between Temporal Measurements and Penetration-aspiration

Langdon, C., \& Blacker, D. (2010). Dysphagia in stroke: a new solution. Stroke Research and Treatment, 2010, 1-6.

Lee, H. J. (2012). The comparisons of the swallowing functions according to the indices in brainstem stroke patients. Korean Journal of Communication Disorders, 17, 377-389.

Loeb, M. B., Becker, M., Eady, A., \& Walker-Dilks, C. (2003). Interventions to prevent aspiration pneumonia in older adults: a systematic review. Journal of the American Geriatrics Society, 51, 1018-1022.

Logemann, J. A., Pauloski, B. R., Rademaker, A. W., \& Kahrilas, P. J. (2002). Oropharyngeal swallow in younger and older women: videofluoroscopic analysis. Journal of Speech, Language, and Hearing Research, 45, 434-445.

Logemann, J. A., Pauloski, B. R., Rademaker, A. W., Colangelo, L. A., Kahrilas, P. J., \& Smith, C. H. (2000). Temporal and biomechanical characteristics of oropharyngeal swallow in younger and older men. Journal of Speech, Language, and Hearing Research, 43, 1264-1274.

Logemann, J. A., Shanahan, T., Rademaker, A. W., Kahrilas, P. J., Lazar, R., \& Halper, A. (1993). Oropharyngeal swallowing after stroke in the left basal ganglion/internal capsule. Dysphagia, 8, 230-234.

Mann, G., Hankey, G. J., \& Cameron, D. (2000). Swallowing disorders following acute stroke: prevalence and diagnostic accuracy. Cerebrovascular Diseases, 10, 380-386.

Marik, P. E. (2001). Aspiration pneumonitis and aspiration pneumonia. New England Journal of Medicine, 344, 665-671.

Martin, R. E., \& Sessle, B. J. (1993). The role of the cerebral cortex in swallowing. Dysphagia, 8, 195-202.

Martino, R., Foley, N., Bhogal, S., Diamant, N., Speechley, M., \& Teasell, R. (2005). Dysphagia after stroke: incidence, diagnosis, and pulmonary complications. Stroke, 36, 2756-2763.

Mosier, K. M., Liu, W. C., Maldjian, J. A., Shah, R., \& Modi, B. (1999). Lateralization of cortical function in swallowing: a functional MR imaging study. American Journal of Neuroradiology, 20, 1520-1526.

Park, T., Kim, Y., \& McCullough, G. (2013). Oropharyngeal transition of the bolus in post-stroke patients. American Journal of Physical Medicine and Rehabilitation, 92, 320-326.
Park, T., Kim, Y., Ko, D. H., \& McCullough, G. (2010). Initiation and duration of laryngeal closure during the pharyngeal swallow in post-stroke patients. Dysphagia, 25, 177-182.

Perlman, A. L., Booth, B. M., \& Grayhack, J. P. (1994). Videofluoroscopic predictors of aspiration in patients with oropharyngeal dysphagia. Dysphagia, 9, 90-95.

Power, M. L., Hamdy, S., Goulermas, J. Y., Tyrrell, P. J., Turnbull, I., \& Thompson, D. G. (2009). Predicting aspiration after hemispheric stroke from timing measures of oropharyngeal bolus flow and laryngeal closure. Dysphagia, 24(3), 257-264.

Robbins, J., \& Levin, R. L. (1988). Swallowing after unilateral stroke of the cerebral cortex: preliminary experience. Dysphagia, 3, 11-17.

Robbins, J., Coyle, J., Rosenbek, J., Roecker, E., \& Wood, J. (1999). Differentiation of normal and abnormal airway protection during swallowing using the penetration-aspiration scale. Dysphagia, 14(4), 228-232.

Robbins, J., Hamilton, J. W., Lof, G. L., \& Kempster, G. B. (1992). Oropharyngeal swallowing in normal adults of different ages. Gastroenterology, 103, 823-829.

Robbins, J., Levine, R. L., Maser, A., Rosenbek, J. C., \& Kempster, G. B. (1993). Swallowing after unilateral stroke of the cerebral cortex. Arch Phys Med Rehabil, 74, 1295-1300.

Rosenbek, J. C., Robbins, J. A., Roecker, E. B., Coyle, J. L., \& Wood, J. L. (1996). A penetration-aspiration scale. Dysphagia, 11, 93-98.

Smithard, D. G., O’Neill, P. A., Martin, D. F., \& England, R. (1997). Aspiration following stroke: is it related to the side of the stroke? Clin Rehabil, 11(1), 73-76.

Suntrup-Krueger, S., Kemmling, A., Warnecke, T., Hamacher, C., Oelenberg, S., Niederstadt, T., ... \& Dziewas, R. (2017). The impact of lesion location on dysphagia incidence, pattern and complications in acute stroke. Part 2: Oropharyngeal residue, swallow and cough response, and pneumonia. European Journal of Neurology, 24, 867-874.

Teasell, R. W., Bach, D., \& McRae, M. (1994). Prevalence and recovery of aspiration poststroke: a retrospective analysis. Dysphagia, 9, 35-39. 


\section{국문초록}

\section{대뇌 손상 위치에 따른 삼킴 시간과 침습 및 흡인 간의 관계}

임익재 ${ }^{1,2} \cdot$ 김향희 ${ }^{3,4} \cdot$ 김현기 $\left.\right|^{2}$ 고명환 ${ }^{25,6}$

${ }^{1}$ 센트럴플로리다대학교 삼킴연구소, ${ }^{2}$ 전북대학교대학원 언어치료학과, ${ }^{3}$ 연세대학교 언어병리학협동과정, ${ }^{4}$ 연세대학교의과대학 재활의학교실, ${ }^{5}$ 전북대학교의과대학 재활의학교실, ${ }^{6}$ 의료기기중개임상시험지원센터

배경 및 목적: 본 연구는 아급성기 편측 반구 뇌졸중 환자의 삼킴 시간이 손상 위치에 따라차이를 보이는지를 조사하고 침습 및 흡인 에 영향을 준 삼킴 시간은 무엇인지를 규명하고자 하였다. 방법: 연구 대상자는 뇌자기공명영상을 통해 편측 반구 손상에 의한 뇌졸중 환자 60명이었으며, 좌반구 손상 환자 집단(27명)과 우반구 손상 환자 집단(33명)으로 분류되었다. 대상자들은 모두 비디오투시조영삼 킴 검사를 수행하였으며 이 검사의 자료로부터 인두통과시간, 후두폐쇄유발시간, 후두폐쇄지속시간, 침습 및 흡인 여부를 조사하였다. 결과: 편측손상 반구에 따라 인두 단계 삼킴 시간은 차이가 없었다. 한편, 우반구 손상 집단의 인두통과시간과 후두폐쇄유발시간은 침 습 및 흡인에 통계적으로 유의한 영향을 주는 것으로 나타났다. 구체적으로, 음식물이 인두 단계를 0.71 초 이내에 통과하지 않으면 침습 및 흡인이 발생하는 것으로 나타났으며 $(\mathrm{AUC}=0.78 ; 95 \% \mathrm{CI}, 0.58-0.96 ; p=.02)$ 과 음식물이 인두 단계에 진입 후 후두 폐쇄 운동이 1.25 초 이내에 일어나지 않으면 침습 및 흡인이 발생하는 것으로 나타났다(AUC $=0.83 ; 95 \% \mathrm{CI}, 0.64-1 ; p=.008)$. 논의 및 결론: 우반구 손 상 환자의 인두통과시간과 후두폐쇄유발시간은 침습 및 흡인을 예측하는 변인이었으며, 이는 우반구가 인두 단계 삼킴 기능에 편향되 어 있기 때문으로 해석된다.

핵심어: 삼킴, 대뇌 오른쪽 손상, 뇌졸중, 침습 및 흡인, 인두통과시간, 후두폐쇄유발시간

본 연구는 제 1 저자의 박사 학위 논문의 일부를 요약한 것임.

본 연구는 한국보건산업진흥원의 지원을 받아수행된 연구임(No. HI15C1529).

\section{참고문헌}

김영선, 박태옥(2007). 정상인에서 연령과 성별에 따른 삼킴 시 후두닫힘 지속시간 비교. 언어청각장애연구, 12, 521-531.

이현정(2012). 뇌간병변 뇌졸중 환자의 병변에 따른 지표별 삼킴기능 비교. 언어청각장애연구, 17, 377-389.

임익재(2017). 천막상 병변 뇌졸중 환자의 삼킴 시간과 흡인에 대한 음식물의 점도 및 양의 효과. 언어치료연구, 26, 133-141. 